\title{
A Stakeholder-Centric Evidence-Guided Model For Management Decisions
}

John Mankelwicz, Troy University - Southeast Region, USA

Robert Kitahara, Troy University - Southeast Region, USA

\begin{abstract}
Managers use a myriad of formal and informal assessment methodologies, both quantitative and qualitative, to make key business decisions when the available data comprise at best "weak signals" of an impending problem and/or opportunity. Accepted paradigms, fundamental theories, and their personal and group frames of reference inform their choice of methods and metrics. Quantification itself and formal methods facilitate the amplification of initial signals into stronger forms, allowing problem identification, and then reformulation, and the activities of the decision chain. This paper develops an evidence-guided model for problem identification and management decisions with focus on the overall stakeholders, rather than purely stockholder model for corporate governance.
\end{abstract}

Keywords: Management decisions, quantitative methods, evidence-guided model, stakeholder

\section{INTRODUCTION}

$\mathcal{J}$ here has been a steady increase in reliance on formal analytical methods and quantitative metrics in both the public and private sectors of modern economies, which have largely moved from material production to data driven operations. Managers receive courses in management science, quantitative methods, operations research, operations management and statistics. Sophisticated theories and techniques allow analyses and decisions that are supportable by numerical data, structured into relevant information. "The numbers" can refer to both of the methods and process of formal analysis, as well as the resultant data outputs that flow both temporally and logically later.

Using exact numbers in discussion clearly reduces ambiguity and apparent uncertainty, and also enhances various mechanisms of cognitive simplification. Virtually every stakeholder group faced by the organization has its preferred (and sometimes unique) metric of organizational performance. The interests of all stakeholders, not just stockholders, must be taken into account (Alpasian, et. al., 2009). In considering stakeholder demands, as in other facets of decision, executives typically proceed through a familiar chain of activities (Gibson, et. al, 1976), in which the recognition of a problem gap is an important early link. However, fast paced environments provide very incomplete information, at least initially. Typically policy makers have only a "weak signal" (Ansoff, 1975) on which to begin the decision process. Data gathering, quantification, and application of theory allow the amplification of weak signals into stronger ones, facilitating problem identification, reformulation, and decision-making (Mankelwicz \& Kitahara, 2008).

Unfortunately, the massive literatures around such rubrics as management decision-making, frames of reference, paradigms, signaling, problem definition, and statistical analysis often seem not to underscore the critical relationships of their subjects to important material outside the rubric (Cascio, 2007). There is a paucity of good integration. This paper will attempt to partially address this gap by considering the role of quantification itself and its important implications for management decision for all stakeholders in the organization. Discussion will first treat the familiar activities of the decision chain, the nature of problem gaps, the concept of signal strength, the role of paradigms, and the importance of feedback. The following section synthesizes these elements into a model. 


\section{PROBLEMS AND DECISIONS}

Quantitative methods are part of managers' efforts to be "intendedly rational;" yet at most they achieve a "bounded rationality (Simon, 1945). Managers seek and use data first to make or ratify decisions, then to "sell" or defend them. They often rely on the release of data to signal a decision, or to effect a feint or bluff. Once implementation activities have provided some knowledge of results (KR), or feedback, they may then seek further information, amend the original decision, or change activities: a new round of decision-making has started.

Essentially numbers are symbols, and symbols may be powerful. At their best, numbers may accurately represent an actual state of affairs or provide the best projection of one. As outputs from quantitative models, numbers can also represent theoretical equilibriums, optima, or desired states. The precision in magnitude, location, and time description of variables is the key to problem formulation (Kepner \& Tregoe, 1965), the foundation of effective managerial decision-making. Further, as symbols, numbers may also cause dread to managers who fear being "pinned down," made prematurely responsible for a course of action because of the numbers they provide.

In the decision making sequence of activities (Gibson, et. al, 1976), the decision making process is "triggered" when a manager or trusted staffer perceives some disturbance or possible opportunity (Segev, 1977). Along with diligence and loyalty, a subordinate's past accuracies in such judgments form the basis of senior managers' trust in their key subordinates; yet these executives judge their subordinates largely from their own personal frames of reference, influenced in turn by paradigm and experience. The chain of decision activity proceeds through identification of a problem gap, the generation, evaluation and selection of solutions, and finally implementation and control. Additional activities guide the process - activities such as information search, criteria selection, and decision ratification.

\section{Response to Weak Signals}

The weak signal concept is an interesting one. This concept is a derived analogy from the hard sciences, especially information and communications theory (Shannon, 1948; Weiner, 1949). Signals pass through established, but finite channels, which are subject to "noise" and error. Through use of filtering mechanisms, proper signals may be distinguished from the surrounding noise (Kalman, 1960). Error correcting codes (Reed \& Soloman, 1960) serve to keep communication moving near the capacity allowed by the channel(s). However, when applied to the non-technical problems facing managers, the use of these rigorous concepts must be considered "metaphorical" (Coffman, 1997).

Writers continue to invoke the weak signal concept in myriad situations, with recent examples ranging from the effectiveness of nursing leaders (Kerfoot, 2003), journalism regarding innovation (Uskali, 2005), the anticipated performance of NFL quarterbacks (Yasinskas, 2008), to the convergence of the IFRS and GAAP accounting practices (Henry, et. al., 2007). However, most discussions do not pursue the analyses rigorously. Indeed, even the extant theory regarding weak signals has to date been thin. Beyond a few accepted accounting or quality control metrics, there is no fully agreed, well developed set of candidate generic signals for managers as they attempt to anticipate problems and opportunities. Managers cannot escape the mindsets of their functional areas, and these mindsets may not always be useful in detecting weak signals. Even managers with rigorous training - so that the mindset might properly be said to approach a paradigm (Kuhn, 1980) - may still miss signals due to the incompleteness of the paradigm itself. More fundamentally, the weak signal concept has not been explicitly articulated to the familiar themes of the decision-making sequence and problem analysis.

Ansoff (1975) provides us with an early and still definitive discussion of this concept for executives. He conceives of the strength of a signal as defined by the level of knowledge it provides the manager. There are five levels. First, there is the sense of a threat or opportunity. Second, the source of changes that produce this threat or opportunity is known. Signals at these levels are considered to be weak. At the third level the nature, magnitude and timing of concrete impacts from the changes are known, at least basically. At level four decision makers have some knowledge of the concrete, alternative courses of action available in response to the changes; they may already be responding. The highest state of knowledge, level five, is one in which the final outcome is known or may be reasonably projected. In Ansoff's parlance, a weak signal is one in which only the general nature of event(s) and possibly the source(s) of changes are known. The signal is at level one or two as defined above. 
Managers may send signals deliberately. They often rely on the release of data to signal some specific decision, e.g., release of a new product. A signal can also be a feint or bluff. Both individuals and organizations may seek ways to signal their possession of some desirable trait, such as integrity, quality, reliability, etc. Thus a manager must be alert to two kinds of signals: those intentionally generated and transmitted by some actor(s), and those that are not intentional and may or may not derive from a specified set of actors. In this discussion, Ansoff (1975) seems to treat weak signals as primarily of the latter kind: perceived by the observer but not necessarily intentional.

Nevertheless, analysis of strategic signals must deal with both kinds of signal. Strategic interactions are by nature situations in which an actor's final outcomes are determined not only by what they do but also by what other actors do (Morgenstern \& von Neumann, 1947; Nash, 1951). Signals, intentional or not, are clearly acts by other actors. In some sense, communication itself may be considered a strategic game. This strategic aspect that gives the topic of weak signals its depth, significance, and great complexity. The complexity is greater yet because the exchange of signals is really occurring not across dyadic linkages, but across a vast network of present and potential stakeholders (Rowley, 1997).

\section{Defining a Problem}

Problems may be considered as "gaps" between desired states of affairs (a goal) and actual states of affairs (Kepner and Tregoe, 1965). Figure 1 depicts a problem gap. Theories, paradigms, and professional experiences provide an idea of desirable levels of referent variables. Managers' experience, their values, and the organizational context suggest what level of deviation from the desired level is within the tolerance limit; this determines which problems managers recognize and accept (Milutinovich \& Mankelwicz, 1983). Similarly, there is a limit to just how closely the actual current state of the variable can be known - the knowledge limit.

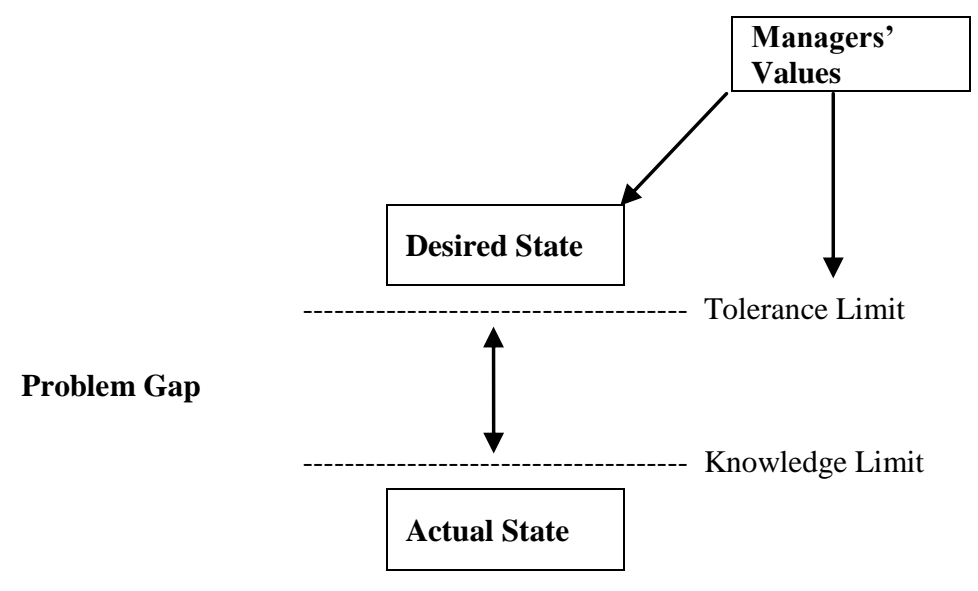

Figure 1. A problem is a gap between a desired state and actual state.

In principle, the problem model will apply to ethical problems as well as practical, factual difficulties. Individuals first become aware of a moral gap between actual behaviors and those presumed under an accepted code. Ethics is essentially a mater of values, obligations, and the relationship between them. Managers' sense of values and obligations play an especially important role in defining the desired state of an ethical problem. After recognizing a moral problem, individuals then pass through stages of moral judgment, intentions to act, and finally actions (Rest, 1986). While practical and ethical problems may have similar logical structure, the discussion will emphasize the difficulties of ethical decision-making. 
Obviously, attempts to quantify ethical issues are still relatively naïve. However, it is events and their potential consequences that trigger both practical and ethical decision-making. The "Moral Intensity" concept of Jones' (1991) Issue Contingent Model provides a way to rate or rank the importance of these consequences. The greater the moral intensity of an issue or problem, the more likely an individual will continue through the steps of this process, proceeding toward actual, intentional moral behaviors. Based on the possible consequences, the moral intensity concept encompasses six measurable dimensions: magnitude of effect, probability of effect, concentration of effect on a specific group(s), social consensus on the issues, immediacy in time, and proximity in space. Of course, the moral intensity of a given issue can vary greatly between stakeholder groups. More than ever it is top management's duty to identify all stakeholders and prioritize them according to salience (Mitchell, et. al., 1997). All must be satisfied at least minimally. Truly salient stakeholders require much more.

Executives' personal characteristics - intelligence and creativity, personality, values, specific abilities and insights, and even social outlook - impact most prominently in the earliest stages of forming the organization's mission and the objectives to meet that mission (Andrews, 1971). Decisions at each sequential stage become less ambiguous and usually more programmed and more dependent upon specific indices or organizational rules. Formal methods and real data drive activity at all levels; this is especially evident for programmed operational decisions.

\section{Paradigms}

How do managers and staff even know which specific variables to consider, observe and measure in the first place? How to measure them? Which constants to assign, which parameters to estimate? Largely they rely on the established theories and practices of their functional areas. Once learned and accepted, these "paradigms" work within the organizational context to give organization members mental schema to guide thought and action. Practitioners can refer to representative works as the "exemplars" of the underlying paradigm (Kuhn, 1980). Thus paradigm and theory inform the search for information, giving meaning to the gathered data in terms of time, setting and people; they allow the data to become true information. Paradigms may also suggest what levels are to be expected or are desirable. This enables formal identification of problem gaps, and intensifies activities in the decision chain. Paradigms, by suggesting relevant variables and methodologies, treat problems as solvable "puzzles", with definite solutions (Kuhn, 1980). Organization culture, politics, and individual differences will of course form the ambiance around these activities.

Accepted paradigms (Kuhn, 1980) and received theory inform decision processes throughout an organization. Indeed these have become institutionalized not only into internal programmed activities, but also into the very social milieu in which the organization functions. Most of these paradigms emerge from a positivist research tradition with emphasis on description, measurement and quantification. Consider finance, marketing, operations etc. All of these functional areas rely on disciplines with accepted paradigms that suggest (even prescribe) the sets of concepts, variables, and methods proper for use in analyses. First, at a macro level, they influence each of the classic five stages of strategic management (Thompson, et. al., 2008). It is through strategic activities that the organization orients itself toward the environment around it. Figure 3 presents the familiar Five Stages, along with the bodies of paradigmatic knowledge that dominate each stage; also, law and / or ethics may become influential at any stage. The stages are sequential, allowing feedback. Each stage can be considered to represent a particular category of decisions. Some variant of this five stage model is appropriate to both public and private administration.

In management deliberation, it is the plausibility and credibility of the numbers that is central. To be credible, the numbers should emerge from an accepted paradigm. That is, the variables used should be encouraged within the paradigm, and the substantive inferences should make sense within the paradigm. Hence, when a manager or staff member uses numbers in an assertion, he is signaling or failing to signal credibility through the very choice or variable he uses. Numbers can actually take on a significance that is somewhat independent of their specific values, or their accuracy. Indeed, at the individual level, psychological aspects of decision-making can combine to reinforce the importance of the numbers to all stakeholders in the organization. 


\section{Feedback}

Philosophers tell us that human experience is continuous, and therefore it is not directly communicated in words. Metaphors allow humans to segment out portions of this experience so that it can be cognitively manipulated and communicated (Langer, 1942). Finding the right metaphor for the situation at hand can be a critical skill for managers or experts to practice their "uncertainty absorption" (March and Simon, 1958). The application of labels and metaphors involve human cognitive (and sometimes physical) activities; in this sense people "socially construct" the environment about them (Berger \& Luckmann, 1967). Combining perceived and constructed views of reality, Weick (1969) suggests that individuals "enact" their environments by acting, perceiving and reacting to the results, and then adjusting. In this sense, metaphors, labels, and assigned numbers are all enacted elements. It is when people interact in communication that shared meanings, environments, and reality emerge (Weick, 1969; Smircich \& Stubbart, 1985; Prahalad \& Bettis, 1986).

Organizations quickly find that mental pictures and good verbal descriptions don't satisfy creditors, auditors or stockholders, or even employees, since these things do not enable communicable performance measurement. At some point the organization must respond: giving dividends, raises, bonuses, or disciplinary measures. The methods and metrics of determining those responses are subject to increasing scrutiny in a litigious world. Numerical data are collected largely to measure and compare performances: of individuals, groups, or the organization as a whole. Performance feedback, or "knowledge of results (KR)," thus becomes a cardinal issue, and Ilgen, et. al. (1979) provides the classic literature synthesis and model for individual level performance feedback. At the level of groups and resource pools performance analysis must also consider both political and psychological factors, and there is often less reliance on "objective" methods of measurement (Castrogiovanni, 1991) or the paradigms underlying those methods. The truly accurate measurement of individual or group performances is not so simple

Both managers and their external stakeholders accept the financial and accounting metrics above as clear performance feedback for the company. The most significant decisions, and those with the greatest long run consequences, are those made by the top management, especially the CEO and those closest to her/him. Stockholders, the financial press, and the board - that can directly ratify the CEO's rewards or administer her/his dismissal - define the performance of the CEO by the performance of the organization. Again, at this level, performances are largely defined by formal, quantitative, and especially financial criteria.

\section{AN EVIDENCE-GUIDED MODEL}

An "evidence-guided" model is one with focus on both the facts from the situation and the inferences, which may be drawn from the relationships delineated in a paradigm. "Evidence" consists of both facts and inferences (Elbing, 1978). Again, problems are "gaps" between some desired state of affairs (a goal) and the actual state of affairs (Kepner and Tregoe, 1965). Progression from an original weak signal (with disturbance known), to discovering the source, to higher states of knowledge allows the identification and refinement of a perceived problem gap. This progression may be long and difficult. Early scanning and search activity will greatly smooth the process (Ansoff, 1975). Managers invoke history, personal experience and familiar paradigms to select initial search variables, methods, and desired states. The model presented as Figure 2 aligns elements of the decision chain, problem definition activity, and states of knowledge.

It is instructive to position these levels of knowledge in relation to the sequential activities of the familiar decision making sequence. Note that Ansoff's (1975) first two levels are usually reached early on, prior to recognition of a definitive problem gap. Weak signals would hence be early in the sequence. To Ansoff, these signals should be an immediate spur to begin information search earlier than otherwise, and the gathered information itself would largely lead to a more thoughtful definition of the gap. To him the difficulty is not necessarily that managers miss weak signals, but that they engage in too little search, too late.

In particular the model specifies that an initial problem definition will precede the advance beyond the weak signal state. Some problem formulation, even a very crude one, is necessary to guide information search. At this point managers rely largely on personal experience; even the choice of an invoked paradigm may be judgmental. Managerial experience and intuition are especially important at this point. An invoked paradigm can 
further guide selection of variables and a desired state, so that a gap may be recognized. Neglecting early data collection and preliminary diagnosis is dangerous, but clinging too tightly to the results of early analysis may be just as perilous.

Clearly, informational search activity is necessary to conduct the initial identification of the problem gap, but often this activity lacks direction and intensity. Organizations will gather much numerical data routinely, but the pace, volume, and scope of collection often intensifies only after definition of a problem gap. Indeed most serious analysis occurs as "problemistic search" (Simon, 1945), in response to a specific emergent problem, which may be prematurely and poorly defined.

\section{Increasing \\ Quantification \\ \& Information}

Feedback monitoring; possible reformulation

Validity concerns, negotiated measures

More intense search; greater quantification; accepted measures at higher level

Formal, intense search; multiple methods

Intuitively select variables and desired state; judgmental choice of paradigm; informal search

Search for source

Ordinary data gathering
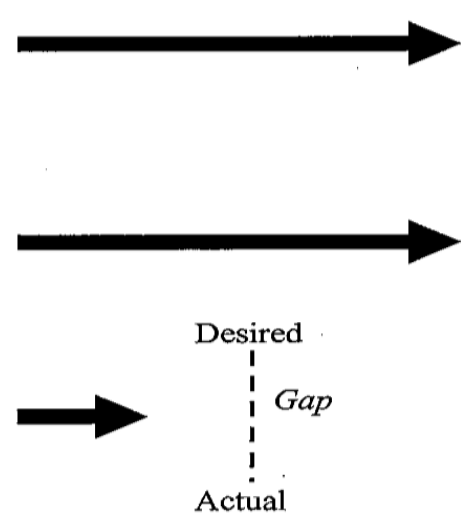

Actual
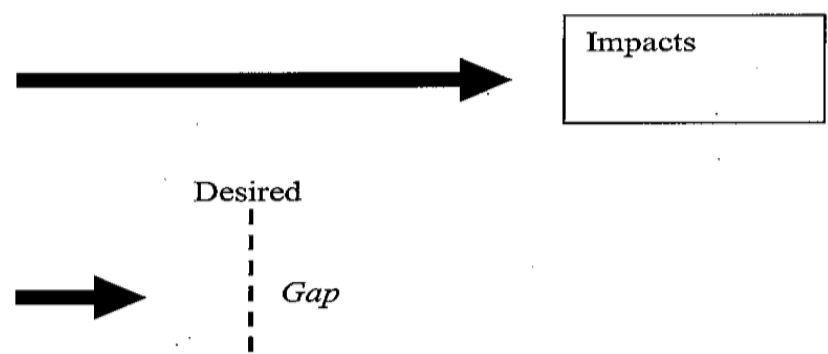

Actual

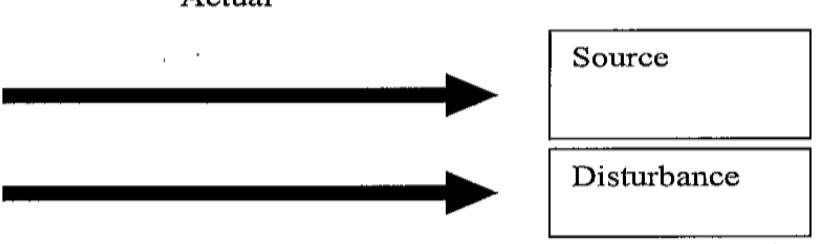

Time

Figure 2. Evidence - guided model of problem definition and management decision. 


\section{Disturbance}

Organizations gather much numerical data routinely. The pace and volume of collection intensifies during periods of serious decision. Typically, the decision making process is "triggered" when a manager or trusted staffer perceives some problem or opportunity (Segev, 1977). Indeed most serious analysis occurs as "problemistic search" (Simon, 1945) in response to a specific event(s), labeled as indicative of an emergent problem. The system for gathering and analysis of information will itself ordinarily tend to make certain information stand out. Nevertheless, not every observer will necessarily see or accept the same "disturbance" in any set of observed outcomes. For many, the signal may be just a vague uneasiness. Individual differences of functional background and personality will be powerful moderators at this first step; indeed, it is possible that the entire sequence may suffer delay or even end here.

\section{Source}

Managers then begin to search for more information regarding the disturbance as well as its source(s). Even when both are known clearly, the problem is still only partially defined: the data indicate only a weak signal. Decision makers are prone to bias at this early stage. They tend to overemphasize numerical data obtained very recently (Boyd, et. al., 1993), or near the start of the formal decision process (Kozielecki, 1972). This bias can restrict the search for information and distort decisions.

Identification of the source has immediate implications. Early labeling of a disturbance as threat, opportunity, or both will be determined by the combination of known events and the source; this combination and attendant labeling may provide the emotional push to trigger problem definition and the decision making process. However, this labeling can be misleading if it is based solely on initial and limited information. When the source is a distrusted person or organization, the situation is especially likely to take on moral overtones; managers in the focal organization may thus prematurely define an ethical problem. Moralizing at the weak signal stage is likely to prove counterproductive.

At this early stage of limited evidence, Attribution Theory (Heider, 1944; Kelley, 1967) would suggest that individual managers reason backwards from the knowledge of results of past episodes to make attributions of the power, motives, and character of the source actor(s), especially when the sources actions are unexpected and chosen without duress (Jones \& Davis, 1965). However, because of the above vulnerability to bias, management probably cannot at this point conduct a full and accurate analysis of stakeholders, their saliencies, or the behavior of any premature coalitions among them.

\section{Problem Identification}

Precise statement of magnitude, location, and time description of variables is the key to problem formulation (Kepner \& Tregoe, 1965), which is the foundation of effective managerial decision-making. While "the numbers" really do matter, the most rigorous and data intensive methods may not be used at this stage. Nevertheless, selection of appropriate variables, search and measurement procedures, and analytical methods greatly facilitate the process of formulating and reformulating the problem gap. Again, paradigms suggest desirable levels of a variable(s) as well as methods for collection and analysis.

Together, experts and managers practice "uncertainty absorption' (March \& Simon, 1958) for the organization. While any subordinate's main task may be to secure the "attention" of superiors (Simon, 1945; Allison, 1971), it is the subordinate's vocal and persistent defense of "the numbers" in her/his area of expertise which convey confidence, desire, and commitment. These latter factors draw the support of project "champions" and ultimately determine ratification of decisions and project funding and (Bower, 1965).

Not all of the inputs into initial problem definition will come from inside the organization. Stakeholders viewed as highly salient, and legitimate stakeholders in coalition with the focal organization will be able to exert influence, shaping the resultant definition. Parenthetically, note that any actor regarded as legitimate in a current coalition with the focal organization will have some degree of salience already (Mitchell, et. al., 1997). Since some 
of these stakeholders may have already begun to communicate or even to prematurely take action - in a possibly knee jerk manner - these actors contribute some degree of turbulence in the external environment. An organization may rely on outside expertise to explicate the situation (Emery \& Trist, 1965), which becomes one of "articulated turbulence."

Decision makers must be particularly on guard at this stage for various forms of cognitive bias. It will be necessary to seek and consider disconfirming as well as confirming information as the problem definition is formed; this activity is very frequently omitted (Bazerman \& Moore, 2009). There is also a common tendency to over rely on data that is readily available, that is considered "representative," or that is considered in some way vivid (Kahnemann \& Tversky, 1979). Bias difficulty is most pronounced when problem definitions are intuited quickly from the top of the organization, and then pontifically announced by superiors with little or no discussion (Pounds, 1969).

\section{Impacts}

Although understanding is still limited after the first problem definition, data is then gathered vigorously. The purpose now is to define the impacts of the perceived problem. Many methodologies may be involved. Since both magnitude and timing must be estimated, both judgmental and statistical forecasting may be involved here. The decision making process may best be described as an amorphous blend of decision-theoretic and intuitive processes.

Numbers can actually take on a significance that is somewhat independent of their specific values, or their accuracy; this is because numbers are essentially symbols, and symbols may be powerful. Accurate numbers represent an actual state of affairs or provide a projection of one. As outputs from quantitative models, numbers also represent theoretical equilibriums, optima, or desired states. As symbols, numbers cause dread to executives who fear being "pinned down," made prematurely responsible for a course of action because of the numbers they provide. This fear is actually desirable if it spurs early and careful information search.

There is also a downside to numerical symbolism. Perhaps the worst case is that these symbols may give emotive force that precipitates the cognitive oversimplifications implied by Prospect Theory, which suggests a tendency to increase the probability of very likely events toward $\mathrm{P}=1.0$, while decreasing the probability of unlikely events, toward $\mathrm{P}=0.0$. The judgmental biases, coalitional politics, and social construction mechanisms discussed above will all influence management's final perceptions. Overall, these mechanisms do not act helpfully toward accurate estimation of impacts. When there is sufficient information to reasonably project the impact(s) from the disturbance, managers begin to reformulate the problem, usually into a more quantifiable form. Note that the impacts are not accomplished facts, but still remain "reasoned conjectures" (de Jouvenel, 1967). However, the quantification process acquires still further momentum. More experts become involved, and data gathering increases yet again. During the process other disturbances may be recognized. Although both managerial experience and paradigmatic knowledge remain important, the balance is shifting towards the latter. This by itself suggests greater attention to quantification. There is also some degree of "political" or "tail guarding" pressure to provide numbers that are recognized measures, from respected paradigms. The level of measurement will be raised, with more observables recorded at the interval or ratio level. Finally, it is almost imperative to know the impact in fairly exact monetary terms, adding further impetus for quantification. The resultant problem reformulation is typically much more complex than the first.

\section{Problem Reformulation}

Thus the model suggests two distinct phases of problem definition. Based on this second formulation, data collection and analysis continues on a larger and more sophisticated basis. New information should eventually allow progression to the fourth level of Ansoff's (1975) signal strength, at which there is knowledge of what must be done. On this basis executives then deliberate and choose an alternative course(s) of action, often with fallback planning. While reaching this fourth level, organizational activity takes on the aspect of paradigm propelled applied research, in that there is considerable attention to the validity of dependent operational measures to indicate that the organization's efforts are working. Clever executives and operatives may carefully negotiate at this point for the use of a favored set of metrics. 
The situation also involves considerable internal signaling and communication within the organization. The exchange of signals and the repeated application of labels and metaphors involve cognitive and physical activities by which people "socially construct" the environment about them (Berger \& Luckmann, 1967). Combining perceived and constructed views of reality, Weick (1969) suggests that individuals "enact" their environments by acting, perceiving and reacting to the results, and then adjusting. It is when people interact in communication that shared meanings and environments emerge (Weick, 1969; Smircich \& Stubbart, 1985; Prahalad \& Bettis, 1986; Nebeker, 2003), and they can perceive signals more readily. Perception of signals is greatly facilitated when data can be interpreted within specific paradigms. Managers' functional backgrounds and personal experiences will have the greatest input on selection of paradigms, variables and methods. However, the organization's culture will also have special influence on this reformulation of the problem, as many groups within the organization will become involved in information search and analysis. Of course the organization's history of interactions with the source will impact what is done. The focal organization's existing coalition partners will be influential in the problem redefinition, although the influence is circular, in that the redefined problem may cause the organization to realign it coalitions.

The influences of paradigm grounded quantification in the public sector play out differently from the private sector, where maximization of long run stock price (under certainty) and short run quarterly profits (under uncertainty) provide the dominant metrics. In both sectors the exact working is modified by a cyclical factor. Public administration is greatly impacted by the zeitgeist focus on efficiency/integrity versus responsiveness (Frederickson, 1996). The private sector equivalent of this is the cyclical market emphasis on efficiency and price versus product differentiation and innovation.

\section{Required Actions}

An organization must explicitly attend to developing it capacity to scan the environment for signals and process the resulting information, as well as developing flexibility (Ansoff, 1975) to withstand the eventual impacts of environmental shocks. Scanning activity will continue, although scanning has already occurred and many scanning mechanisms are already in place as the organization begins to examine possible active responses and select a course of action. Hence, the organization is seeking flexibility, and considering alternative actions to counter the threat or seize the opportunity. Activities to build flexible response may involve structural, technical, or even cultural change will require planning before implementation. They will also involve reliance in the organization's network of external contacts. If the source of the perceived disturbance is considered potent and hostile, the organization may consider direct market responses or possibly legal action.

\section{Final Outcomes}

The progression to the fifth and last state of knowledge, regarding final outcomes, is likely to be relatively long. Organizational members are acting as well as searching and analyzing. Returning to Weick's (1969) terms, managers first act, and then perceive and interpret the results of their own activity and others' responses (feedback), and then adjust their actions and perceptions. These steps of "enactment" are guided by paradigm, accepted theory, and their own experience that provides the desiderata from prior enactments. Managerial and staff activities become still more directed, with yet more intensive data gathering. Measurement is more sophisticated, with most variables at an interval or ratio level. Management has now committed to a course of action. Accordingly, activities will have a more visible and public character than those earlier in the sequence. External stakeholders and the relevant parts of the press are watching. Reputations and careers may be on the line. Paradigms continue to guide search and decision, but now paradigms take on a protective, legitimizing role as well as a substantive one.

This is the implementation and control stage. Management begins to install formal mechanisms. External scanning continues, but the activities here now involve the gathering and interpretation of formal feedback. The process is clearly influenced by the dynamics and psychological processes of feedback as well as by the organization's culture. The organization takes in more data, but may or may not employ more powerful statistical methods. In formalizing variables for feedback, paradigms and attendant procedures do somewhat ameliorate blind spots in managers' personal frames of reference. In principle less valuable feedback will go unnoticed because an individual cannot separate the personal source of the feedback from its message content. The feedback is now more cleari, precise, and hopefully timelier. If initial results suggest that organizational efforts will be successful, 
everyone will part of the credit before the attention at the top of the organization shifts elsewhere (Allison, 1971). In consequence, real monitoring efforts may then slacken even as data proliferates. However, the feedback may not indicate successful efforts; it may even become necessary to cycle back, to seriously reformulate the problem. This is vital.

Failure to perceive, accept and act on feedback from implantation activities can be disastrous, and even CEO's may be at fault here. First, with a reputation to uphold, they may succumb to Kelley's (1967) "fundamental attribution error," blaming poor performance by others to deficiencies in character or ability, yet assigning their own poor failures to unfavorable situations. Indeed, it is possible that they be more susceptible to this malaise.

While other employees perceive several feedback dimensions, they weight most highly the negative feedbacks from objective standards and then social feedback from supervisors and coworkers (Herold \& Greller; 1977). On the other hand, financial services CEO's seemed to recognize still more dimensions of feedback, yet weighted positive feedback from both objective numbers and from social sources overwhelmingly highly (Mankelwicz, et. al., 1987). A personality test indicated that more masculine CEO's especially neglected all negative feedback. Prospect theory (Kahneman \& Tversky, 1979) asserts that individuals "frame" a situation in terms of gains and losses, with a definite zero or neutral point. Confronted with "loss" outcomes, people take risks to avoid the loss. Prospect Theory thus suggests that CEO's seek to avoid the eminent loss at the risk of a possibly greater loss later. By failing to undertake need problem reformulation, managers escalate commitments to failing projects when it was clearly possible to learn from initial setbacks (Staw \& Ross, 1978).

\section{AN EXAMPLE}

In the early 1980's the LTV Corporation was involved in the production of steel products through its ownership of the Jones and Laughlin Steel Company. LTV Corporation merged Jones and Laughlin with Republic steel in 1984, forming LTV Steel, the second largest steel company in the US. Both component companies were then losing hundreds of millions of dollars annually in a global economic environment within which most US companies were floundering because of their antiquated facilities and complex supply chains. LTV executives justified this merger using formal quantitative techniques focused on economies and complementary product lines resulting from the merger. There was intense lobbying at the highest administrative and legislative levels. The merger plans were controversial, with great debate over potential anti-trust violations. After much wrangling, the merger was ultimately approved (Time, 2004).

Despite the grandiose plans and hoopla over the merger LTV Steel lost $\$ 630$ million in the first six months of 1985 and began cost cutting measures that included reductions in employee benefits and pensions (LA Times, 1985). In 1986 the company filed for Chapter 11 protection and reorganization - just two short years after the merger. This was one of the largest such filings in corporate history. The company sold many of its assets to pay its debts and reorganized to focus on flat-rolled and tubular steel products. Like most of the US steel industry at the time LTV faced immense pressure from foreign competitors and continued to lose money (Western Reserve Historical Society, n.d.). By the year 2000 the company had lost money every quarter over a two year period and called upon its lenders and the US government for financial support to avert complete collapse (Miller, 2000). In 2001 the company once again filed for bankruptcy protection.

LTV's bankruptcy is a bellwether case, becoming one of the first large corporations to use Chapter 11 bankruptcy to abandon retiree pensions and benefits (PBS, n.d.). The government-run Pension Benefit Guaranty Corporation (PBGC) took ownership of three of LTV Steel's pension plans (Jorden, 1988). The bankruptcy also called into question the financial practices of many organizations in developing "asset-backed securitization" mechanisms to render assets "bankruptcy-remote" essentially removing such collateral from their bankruptcy estate (Stark, 2002). Beyond the financial and legal ramifications are the human and ethical implications: many LTV steel employees lost their health benefits, retirements and livelihoods.

Although LTV blamed its failure on unfair competitive practices from foreign competitors and governments that allowed them to dump steel on US markets cheaper than LTV could produce them, many argue that LTV grossly mismanaged the crisis (Parker, 2002). LTV executives made numerous strategic decisions that 
exacerbated the problems, purchasing additional steel companies that lost millions more and grossly overpaying for others.

\section{DISCUSSION}

Adaptability to rapid, often unpredictable change is a key requirement for survival of both individual managers and entire organizations. Organizational learning (Paton \& McCalman, 2008) is an important element of adaptability, but it requires unlearning of old behaviors, technologies, and culture (Prahalad \& Bettis, 1995); the degree of learning possible during any interval is a function unlearning during the previous interval. There is an "unlearning curve." Careful quantification can actually facilitate required unlearning, because numbers allow more precise description of what must be unlearned. The idea is to undertake unlearning while it need not be severe abolishing entire departments and divisions. Judicious problem identification involves considerable organization as it proceeds through the stages, providing increased knowledge. The trouble with LTV is not that it did not use quantitative methods, but rather that it defined problem issues sloppily, ignored feedback, failed to unlearn and learn, and increased commitment to a failing course of action.

The LTV Steel example provides an interesting and current perspective on the nature and impacts of strategic management decisions in the face of market and environmental uncertainties as well as forming a framework for discussing the implications of the evidence-guided model discussed above. The lessons of this example include:

- $\quad$ Formal quantitative theory and procedures are often used to establish the basis for rational management decisions. LTV management relied on textbook economies of scale to justify its merger.

- $\quad$ The numbers can be manipulated to rationalize otherwise sound decisions. Despite known competitive pressures, environmental circumstances, and legislative constraints LTV managed to obtain approval from its stakeholders and the government to proceed with the merger of two large unprofitable organizations.

- $\quad$ Decisions are frequently made with varying degrees of uncertainty in the environmental moderators, i.e. weak strategic signals. In this instance global market forces were highly speculative.

- Moderating factors often emerge from many sources. LTV's merger would not have occurred without its high-pressure lobbying and intervention at the highest levels of government.

- $\quad$ Paradigmatic knowledge plays a key role in the decision and feedback processes. LTV brought to bear all its imbedded organizational knowledge to develop and justify its strategic plans for the merger.

- The ability to adapt to change and uncertainty is a fundamental requirement for all decision makers. The US steel industry could not reverse the effects of competitive actions of foreign companies and governments. LTV managers did not reformulate their key problems; they engaged in escalating commitments to failing strategies.

- The potential for organizational and ethical failures is large in a high-stakes environment. The failed merger resulted in tens of thousands of layoffs and lost benefits for LTV steel employees.

Business and government have now long institutionalized many useful numerical, monetized metrics into accepted practice. These indices include stock price, reported profit, ROA, risk adjusted measures, quick ratio, and market share, among others. Fraudulent distortion of these respected indices is possible when data is over aggregated. There is also sometimes a faulty correlation between an intended concept and its accepted measure (Boyd, et. al., 1993). Managers can thus appeal to respected measures to conceal or misrepresent facts. All of these things seem to have occurred at LTV. Nevertheless, the quality of procedures, measures, and controls ultimately insures such deceptive success is temporary. Magnitude of effect and a general social consensus on an issue increase moral awareness of an issue, as long as discussion employ moral language explicitly (Butterfield, et. al., 2000). Aspects of organizational context may impede intention ever becoming behaviors (Jones, 1991). Personality traits interact with Jones' (1991) Moral Intensity dimensions (Trevino, et. al. 2006); in particular, "Utilitarians" become aware of fewer moral issues than "Formalists" (Reynolds, 2006). Indeed, a stakeholder model may be a more ethical, efficient choice of corporate governance (Alpasian, et. al., 2009). Decisions must be made in the context of all those who have an interest, i.e. all stakeholders in the endeavor. 


\section{AUTHOR INFORMATION}

Dr. John Mankelwicz is an Associate Professor in Business at Troy University. His research encompasses a multitude of topics in management, including environmental scanning and weak signals, strategic flexibility, decision-making, business ethics, ecological impacts, and the use of film in business education. He has published numerous papers in peer-reviewed conferences and refereed journals. His contact information is: Troy University, 21 N. New Warrington Rd, Pensacola, FL, 32506, 850-458-4732, mailto: jmmank@troy.edu

Dr. Robert Kitahara is an Associate Professor of Business at Troy University - Southeast Region. He received his $\mathrm{Ph} . \mathrm{D}$. in Electrical Engineering (Automatic Control/Artificial Intelligence) from Purdue University, MS Systems Management from the Florida Institute of Technology, and MBA from the Florida Institute of Technology. He is the Business Programs Coordinator for the Ft. Walton Beach, Florida area. His current research interests include; business/management, technology management, quantitative methods, academic integrity and distance learning.

\section{REFERENCES}

1. Allison, G. T. (1971) Essence of decision: Explaining the Cuban missile crisis. Boston: Little, Brown.

2. Andrews, K. R. (1971) The concept of corporate strategy. Homewood, Ill., Dow Jones-Irwin.

3. Alpasian, C., Green, S., Mitroff, I. Corporate Governance in the Context of Crises: Towards a Stakeholder Theory of Crisis Management, Journal of Contingencies and Crisis Management, 17(1), 38-49.

4. Ansoff, H. I. (1975) Managing Strategic Surprise by Response to Weak Signals. California Management Review, 18(2):21-23.

5. Bazerman, M. H. \& Moore, D. A. (2009) Judgment in managerial decision making. Hoboken, NJ: John Wiley.

6. Berger, P. L. \& Luckmann, T. (1967) The social construction of reality: A treatise on the sociology of knowledge. Garden city, NY: Anchor

7. $\quad$ Bower, J. L. (1965) Managing the resource allocation process. Homewood, Ill.: Irwin

8. Boyd, B. K., Dess, G. G. \& Rasheed, A. M. A. (1993) Divergence between archival and perceptual measures of the environment: Causes and consequences. Academy of Management Review, 18: 204-226.

9. Butterfield, K. D., Trevino, L. K. \& Weaver, G. R. (2006) Moral Awareness in Business Organizations: Influences of Issue-related and Social Context Factors. Human Relations, 53: 981-1018.

10. Cascio, W. F. (2007) Evidence-Based Management and the Marketplace for Ideas. Academy of Management Journal. 50:1009-1012.

11. Castrogiovanni, G. J. (1991) Environmental munificence: A theoretical assessment. Academy of Management Review, 16: 542-565.

12. de Jouvenel, B. (1967) The art of conjecture. London: Basic Books.

13. Elbing, A. O. (1978) Behavioral decisions in organizations. $2^{\text {nd }}$ ed., Oakland, New Jersey: Scott, Foresman $\&$ Co.

14. Emery, F. E. \& Trist, E. L. (1965) The Causal Texture of Organizational Environments. Human Relations. 118(1), 21-32.

15. Frederickson, H. G. (1997) The spirit of public administration. San Francisco: Jossey-Bass.

16. Gibson, J. L., Ivancevich, J. M. \& Donnelly, Jr. J. H. (1976) Organizations: Behavior, structure, processes. Dallas: Business Publications, Inc.

17. Heider, F. (1944) Social Perception and Phenomenal Causality. Psychological Review, 51: 358-74.

18. Henry, E., Lin, S. W. \& Yang, Y. (2007) Weak Signal: Evidence of IFRS and U.S. GAAP Convergence from Nokia's 20-F Reconciliations. Issues in Accounting Education. 22(4):709-720.

19. Herold, D. \& Greller, M. (1977) Feedback: The Definition of a Construct. Academy of Management Journal. 20: 142-147.

20. Ilgen, D. R., Fisher, C.D. \& Taylor, M. S. (1979) Consequences of Individual Feedback on Behavior in Organizations. Journal of Applied Psychology, 64(4):349-371.

21. Ilgen, D. R., Barnes-Farrell, J. L. \& McKellin, D. B. (1993) Performance Appraisal Process Research in the 1980's: What Has It Contributed to Appraisal in Use? Organizational Behavior and Human Decision Processes, 54: 321-68. 
22. Jones, E. E. \& Davis, K. E. (1965) From Acts to Dispositions: The Attribution Process in Person Perception. In L. Berkowitz (ed.) Advances in experimental social psychology, vol. 2, New York: Academic Press.

23. Jones, T. M. (1991) Ethical Decision making by Individuals in Organizations: An issue-contingent model. Academy of Management Review, 16:366-395

24. Jorden, J. (1988). The Washington Post. LTV's Bankruptcy Reorganization Plan Envisions No More Layoffs or Closings. Retrieved December 5, 2009 from http://www.encyclopedia.com/doc/1P21255033.html.

25. Kahnemann, D. \& Tversky, A. (1979) Prospect Theory: An Analysis of Decisions Under Risk. Econometrica, 47: 263-291.

26. Kalman, R.E. (1960). "A new approach to linear filtering and prediction problems". Journal of Basic Engineering 82 (1): 35-45.

27. Kelley, H. H. (1967) Attribution Theory in Social Psychology, in D. Levine (ed.), Nebraska Symposium on Motivation, 15: 192-240, Nebraska: University of Nebraska Press.

28. Kepner, C. H. \& Tregoe, B. B. (1965) The rational manager. New York: McGraw-Hill.

29. Kerfoot, K. (2003) Attending to weak signals: the leader's challenge. Nursing Economics. Nov.-Dec.: 1-4.

30. Kozielecki, J. (1972) A Model for Diagnostic Problem Solving. Acta Psychologica, 36: 370-380.

31. Kuhn, T. S. (1980) The structure of scientific revolutions. Chicago: U. Chicago Press.

32. Langer, S. 1942. Philosophy in a new key. Cambridge, Mass.: Harvard University Press.

33. 8,000 Workers at LTV Steel Face Pay Cuts (1985, August 30). Los Angeles Times, p. 7.

34. Mankelwicz, J. M., Boseman, F. G. \& Milutinovich, J. S. (1987) Strategic Feedback: A Construct Definition, Proceedings. Pacific Conference, Decision Sciences Institute.

35. Mankelwicz, J. M. \& Kitahara, R. (2008) Propositions to Guide Evidence-Based Decision-Making. Journal of Business and Economics Research. 6(10): 41-55.

36. March, J. G. \& Simon, H. A. (1958) Organizations. New York: John Wiley

37. Miller, L. (2000). AccessMyLibrary. Bank bailout keeps LTV steel mills humming. Retrieved December 5, 2009 from http://www.accessmylibrary.com/coms2/summary 0286-1900507 ITM

38. Milutinovich, Y. S. \& Mankelwicz, J. M. (1983) Problem/Opportunity Identification When Signals are Weak or Non-existent. Proceedings, Third International Symposium on Forecasting. Philadelphia: International Institute of Forecasters.

39. Mitchell, R. K., Agle, B. R. \& Wood, D. J. (1997) Toward a Theory of Stakeholder Salience: Defining the Principle of Who and What really counts. Academy of Management Review, 22: 853-886.

40. Nebeker, D. M. (1975) Situational favorability and perceived environmental uncertainty. Administrative Science Quarterly, 20: 281-294.

41. Parker, R. (2002). LaborNotes. Steel Crisis Deepens As LTV Shuts Down; Health Care and Pensions Benefits in Danger. Retrieved December 5, 2009 from http://labornotes.org/node/1093

42. Paton, R. A. \& McCalman, J. (2008) Change management: A guide to effective implementation. $3^{\text {rd }}$ ed. Los Angeles: SAGE.

43. PBS (n.d.). Frontline: LTV's Bankruptcy - A Bellwether case. Retrieved December 5, 2009 from http://www.pbs.org/wgbh/pages/frontline/retirement/stories/

44. Pounds, WF. The Process of Problem Finding. Industrial Management Review, 1969, 11, 1-19.

45. Prahalad, C. K. \& Bettis, R. A. (1986) The dominant logic: A new linkage between diversity and performance. Strategic Management Journal, 7: 485-501.

46. Reed, I.S. and G. Soloman (1960) Journal of the Society for Industrial and Applied Mathematics. June.

47. Rest, J. R. (1986) Moral development: Advances in research and theory. New York: Praeger.

48. Reynolds, S. J. (2006) Moral Awareness and Ethical Predispositions: Investigating the Role of Individual Differences in the Recognition of Moral Issues. Journal of Applied Psychology, 91(1):233-243.

49. Smircich, L. \& Stubbart, C. (1985) Strategic management in an enacted world. Academy of Management Review, 10: 724-736.

50. Segev, E. (1977) Triggering the Decision-making Process. Management Decision, 14(5):229-238.

51. Shannon, C.E., "A Mathematical Theory of Communication", Bell System Technical Journal, vol. 27, pp. 379-423, 623-656, July, October, 1948

52. Simon, H. A. (1945) Administrative Behavior. New York: Free Press. 
53. Stark, R. (2002). Viewing the LTV Steel ABS Opinion in its Proper Context. The Journal of Corporate Law, 27(2), 211-229.

54. Staw, B. M. \& Ross, J. (1978) Commitment to a Policy Decision: A Multi-theoretical Perspective. Administrative Science Quarterly, 23: 40-64.

55. Thompson, Jr. A. A., Strickland, III A. J. \& Gamble, J. E. (2008) Crafting and executing strategy. New York: McGraw-Hill/Irwin.

56. Justice says yes to LTV Steel. (1984, April 2). Time Magazine

57. Uskali, T. (2005) Paying Attention to Weak Signals - The Key Concept for Innovation Journalism. Innovation Journalism, 2(4): 33-52.

58. Weick, K. E. (1969) The social psychology of organizing. Reading, MS: Addison-Wesley.

59. Western Reserve Historical Society. (n.d.) LTV Steel: About LTV Steel. Retrieved December 5, 2009 from http://www.wrhs.org/index.php/crawford/Online Exhibit/Clev_Steel/LTV

60. Yasinskas. P. (2008) Weak signals: Several teams face QB issues this off-season. ESPN.com 